\title{
The use of fluorescently-tagged apoptolidins in cellular uptake and response studies
}

\author{
Katherine M Chong ${ }^{1,2}$, Nalin Leelatian ${ }^{1,3}$, Sean M Deguire ${ }^{1,2}$, Asa A Brockman ${ }^{3}$, David Earl ${ }^{1,2}$, \\ Rebecca A Ihrie ${ }^{2,3}$, Jonathan M Irish ${ }^{1,3}$, Brian O Bachmann ${ }^{1,4}$ and Gary A Sulikowski ${ }^{1,4}$
}

The apoptolidins are glycomacrolide microbial metabolites reported to be selectively cytotoxic against tumor cells. Using fluorescently tagged active derivatives we demonstrate selective uptake of these four tagged glycomacrolides in cancer cells over healthy human blood cells. We also demonstrate the utility of these five fluorescently tagged glycomacrolides in fluorescent flow cytometry to monitor cellular uptake of the six glycomacrolides and cellular response.

The Journal of Antibiotics (2016) 69, 327-330; doi:10.1038/ja.2016.22; published online 9 March 2016

\section{INTRODUCTION}

Apoptolidin A, isolated from an actinomycete (FU 40), was reported to selectively induce cell death in E1A and E1A/E1B19K transformed rat glia cells, while normal rat glia and $3 \mathrm{Y} 1$ fibroblast cells were found to be non-responsive to apoptolidin A. ${ }^{1}$ The pathway of cell death was proposed to be apoptosis based on observed cell morphology and DNA laddering. Khosla and Salomon later demonstrated apoptolidin A induced apoptosis in LYas mouse lymphoma cells via mitochondrial pathway. ${ }^{2,3}$ In early 2015, Ishmael and co-workers demonstrated apoptolidin A treatment to several tumor cell lines in culture, caused a shift in cellular metabolism and status of AMP-activated protein kinase (AMPK) stress pathway leading to autophagy as characterized by increased phosphorylation of AMPK (Thr 172), acetyl-CoA carboxylase (ACC), and Unc-51 like autophagy activating kinase (ULK). ${ }^{4}$ The observed effects were consistent with ATP synthase (mitochondrial respiration) inhibition as a mode of action. ${ }^{2,3}$

Since the original isolation of apoptolidin A, over eight congeners have been produced by fermentation, ${ }^{5-10}$ mutasynthesis, precursor directed biosynthesis, ${ }^{11,12}$ and chemical synthesis (Figure 1). ${ }^{13-15}$ Accompanying cell cytotoxicity studies have demonstrated the need for deoxy sugars to observe cellular activity, as the aglycone (apoptolidinone) has shown no activity $\left(\mathrm{EC}_{50}>10 \mu \mathrm{M}\right)$ in a variety of tumor cell lines (for example, H292, breast, and HCT 116). ${ }^{14,15}$

Dye labeled small molecules enable visualization of cellular uptake, localization and selective response studies using confocal microscopy. We had prepared cyanine-3 (Cy3) conjugates of apoptolidin A and $\mathrm{H}$ enabling cellular localization studies that demonstrated localization in the mitochondria using H292 cells. ${ }^{16}$ Recently, Hecht and co-workers demonstrated using dye-labeled conjugates of bleomycin and its corresponding aglycone (deglycobleomycin), the selective uptake of the former by cancer cells in cell culture. ${ }^{17-20}$ We reasoned similar studies could be conducted using $\mathrm{Cy} 3$ apoptolidins $\mathrm{A} / \mathrm{H}$ in cell culture leading to a possible explanation of the observed cell selectivity as described in the original isolation paper. Furthermore, we employed fluorescent flow cytometry to monitor cellular uptake of fluorescent apoptolidin probes in a high-throughput, single-cell format.

\section{MATERIALS AND METHODS}

Production and chemical synthesis of apoptolidins and fluorescent derivatives

Apoptolidins $\mathrm{A}$ and $\mathrm{H}$ were produced by fermentation of the apoptolidin producer FU 40 and a mutant strain (ApoGT2 knockout) at Vanderbilt University. Cyanine- 3 derivatives of apoptolidin $\mathrm{A}$ and $\mathrm{H}$ were prepared by semi synthesis as described earlier.

Uptake of apoptolidins $\mathrm{A}$ and $\mathrm{H}$ in various cell types Human cancer cell lines and peripheral blood mononuclear cells (PBMCs) were used to characterize uptake of apoptolidin A and apoptolidin $\mathrm{H}$. The following cell lines were included: SW620 (colon cancer), U87-MG (glioblastoma), LN229 (glioblastoma), and A549 (lung adenocarcinoma). Cell lines were cultured under ATCC recommended protocols. Cells were detached using Trypsin and resuspended in recommended culture media at $1 \times 10^{6} \mathrm{cells} \mathrm{ml}^{-1}$ prior to drug treatment. Human PBMCs were collected from a healthy donor, following the protocols approved by Vanderbilt University Medical Center Institutional Review Board, processed by standard Ficoll preparation protocol, and cryopreserved in liquid nitrogen. PBMCs were thawed and resuspended in warm RPMI 1640 media containing $10 \%$ FBS at $1 \times 10^{6}$ cells ml $^{-1}$ prior to drug treatment. Cells were treated with either vehicle dimethyl sulfoxide (DMSO), $1 \mu \mathrm{M}$ of $\mathrm{Cy} 3$ apoplolidin $\mathrm{A}$, or $1 \mu \mathrm{M}$ of $\mathrm{Cy} 3$ apoptolidin $\mathrm{H}$ for $1 \mathrm{~h}$ at

${ }^{1}$ Vanderbilt Institute of Chemical Biology, Vanderbilt University Medical Center, Nashville, TN, USA; ${ }^{2}$ Department of Neurological Surgery, Vanderbilt University Medical Center, Nashville, TN, USA; ${ }^{3}$ Department of Cancer Biology, Vanderbilt University Medical Center, Nashville, TN, USA and ${ }^{4}$ Department of Chemistry, Vanderbilt University, Nashville, TN, USA

Correspondence: Professor GA Sulikowski, Department of Chemistry, Vanderbilt University, 12415 Medical Research Building IV, 2213 Garland Avenue, Nashville, TN 37232 , USA.

E-mail: gary.a.sulikowski@vanderbilt.edu

The paper is dedicated to Professor Amos B Smith, III in recognition of 50 years of research and education in the areas of Natural Product Total Synthesis, Bioorganic and Medicinal Chemistry.

Received 13 December 2015; revised 25 January 2016; accepted 1 February 2016; published online 9 March 2016 


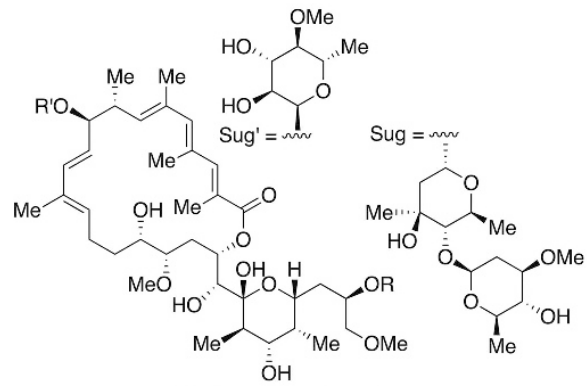

apoptolidin A: R' = Sug'; R = Sug apoptolidin $\mathrm{H}^{\prime} \mathrm{R}^{\prime}=$ Sug'; $\mathrm{R}=\mathrm{H}$ apoptolidinone: $R^{\prime}=R=H$

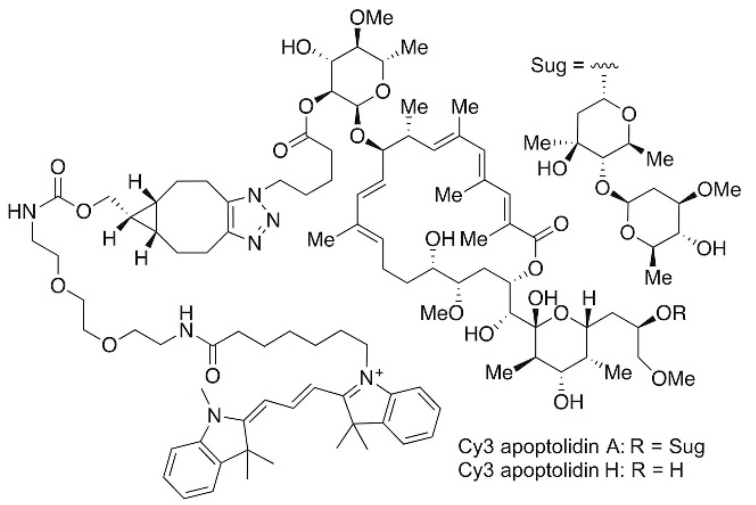

Figure 1 Apoptolidins and fluorescent derivatives.
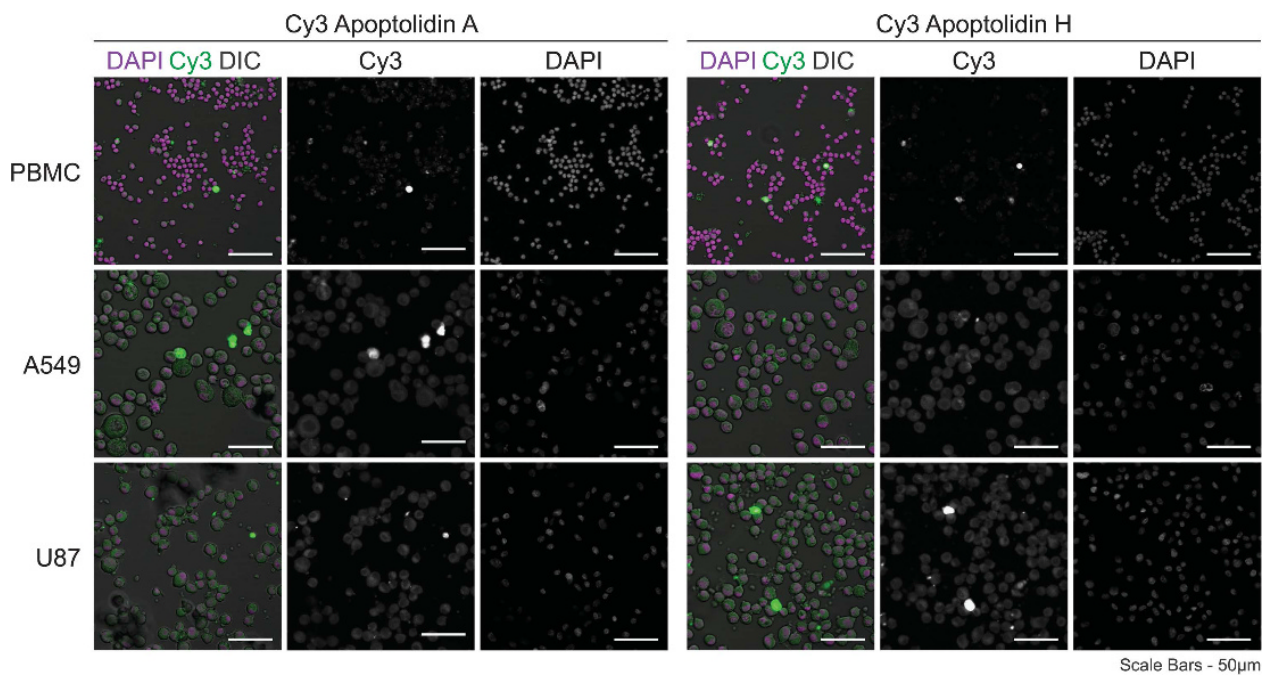

Figure 2 Differential uptake of Сy3 apoptolidins by tumor cells relative to healthy blood cells. Confocal images of different human cell types showing minimal Cy3 apoptolidins uptake (green) by healthy PBMCs and higher uptake in A549 and U87 cells. Nuclei were stained with diaminophenylindole (pink). Scale bars $=50 \mu \mathrm{m}$. DIC, differential interference contrast.

$37^{\circ} \mathrm{C}$. Cells were washed twice in PBS and fixed with $1.6 \%$ paraformaldehyde for $10 \mathrm{~min}$ at room temperature, and were permeabilized with ice-cold methanol for $30 \mathrm{~min}$.

\section{Fluorescent flow cytometry}

After methanol permeabilization, cells were stained with 1:250 anti p-ACC antibody (cell signaling) for $30 \mathrm{~min}$ in the dark at room temperature. Cells were then stained with 1:1000 Donkey anti-Rabbit Ax647 (Life Technologies, Carlsbad, CA, USA) for $30 \mathrm{~min}$ in the dark at room temperature, and were washed and resuspended in PBS for analysis on 5-laser BD LSRII (BD Biosciences, San Jose, CA, USA) at the Vanderbilt Flow Cytometry Shared Resource and evaluated using the Cytobank software (Mountain View, CA, USA). Untreated cells were stained with only the secondary antibody and used as negative control.

\section{Confocal microscopy}

The stained cell suspensions described above were incubated with diaminophenylindole at $1 \mu \mathrm{g} \mathrm{ml}^{-1}$ for $10 \mathrm{~min}$ at room temperature, and placed on glass slides for imaging on an LSM 710 META inverted microscope (Zeiss, Oberkdochen, Germany) at the Vanderbilt Cell Imaging Shared Resource. Data were analyzed using Zen 2011 software.

\section{RESULTS AND DISCUSSION}

In earlier work we determined (using $\mathrm{Cy} 3$ ) that apoptolidin $\mathrm{A}$ and $\mathrm{H}$ localized in the mitochondria of human lung (H292) tumor cells using confocal microscopy. ${ }^{16}$ This observation is in complete agreement with earlier reports describing apoptolidin A as a potential ATP synthase (oxidative phosphorylation) inhibitor. ${ }^{2,3}$

In the original isolation paper and later when evaluated against the National Cancer Institute 60 (NCI-60) human cancer cell line panel, apoptolidin A was described as a selective inhibitor of cell growth. ${ }^{1-3}$ Cell selectivity can be imparted by either selective cell uptake and/or targeting of cell phenotype (for example, metabolic state of a tumor cell). Hecht and co-workers have demonstrated cyanine tagged bleomycin is selectively taken up in most cancer cell lines in comparison with 'normal' cell counterparts in cell culture. ${ }^{19,20}$ However, these studies determined the activity of compounds, including apoptolidin, after long-term treatment (2-6 days) of cells in vitro. Here, we aimed to characterize the immediate uptake of apoptolidin $\mathrm{A}$ and $\mathrm{H}$ by different human cell types, as well as their signaling responses to the treatment.

We used confocal fluorescent microscopy to characterize the uptake of $\mathrm{Cy} 3$ apoptolidin $\mathrm{A}$ and $\mathrm{H}$ in healthy PBMCs and human lung adenocarcinoma (A549) and human glioblastoma (U87) tumor cells after 1-hour treatment (Figure 2). The confocal images revealed minimal uptake of Cy3 apoptolidins by healthy PBMCs, but higher uptake of Cy3 apoptolidins by A549 and U87 tumor cells. 


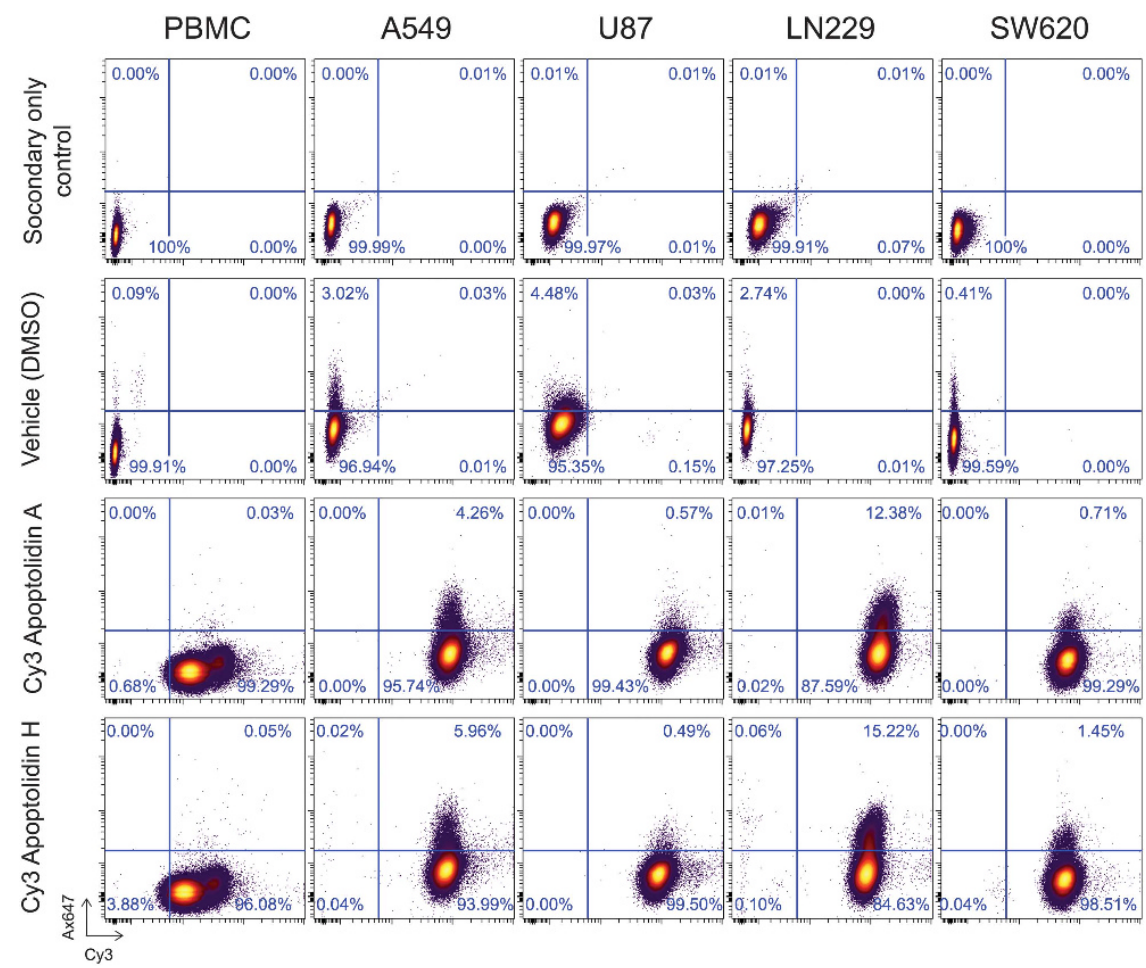

Figure 3 Fluorescent flow cytometry used to monitor cellular uptake of Cy3 apoptolidins and phosphorylation of ACC (Ser79). Biaxial contour plots are shown to represent cell density (heat).

Fluorescent phospho-specific flow cytometry (phospho-flow) employs fluorescently tagged antibodies to dissect activation of cell signaling pathways in single cells in response to treatment with small molecules including natural products. ${ }^{21}$ As fluorophores with different emission wavelengths can be monitored in different channels the uptake of fluorescent small molecules can be monitored as well as cell response. For example, the cellular uptake of fluorescent anticancer agents such as daunomycin as well as fluorescent nanoparticles has been monitored by traditional flow cytometry. ${ }^{22,23}$ Phospho-flow allows quantitative measurement of activated signaling responses of individual cells to external stimuli, such as drug treatment. Often patient-derived tumor cells contain a heterogeneous mix of different cell subsets, which can harbor distinct sensitivity to exogenous agents. Apoptolidin A and C sensitive cell lines including glioblastoma (U87), were reported to undergo autophagy by way of AMPK activation, as indicated by increased phosphorylation of AMPK (Thr 172), ACC (Ser79), and ULK1 (Ser555). ${ }^{4}$ In earlier publications colon cancer SW620 cells were reported as apoptolidin A sensitive, while A549 cells appeared apoptolidin A insensitive when evaluated in the NCI-60 cell line. ${ }^{2}$ Using phospho-flow, we monitored cell uptake of Cy3 apoptolidins and phosphorylation of ACC after short-term $(1 \mathrm{~h})$ treatment with vehicle (DMSO) or apoptolidins (Figure 3). We examined the response of healthy PBMCs, glioblastoma (U87 and LN-229), lung adenocarcinoma (A549), and colorectal (SW620) tumor cell lines to Cy3 apoptolidins $\mathrm{A}$ and $\mathrm{H}$.

After $1 \mathrm{~h}$ of treatment, healthy PBMCs and all four cancer cell lines showed almost complete (>98\%) uptake of Cy3 apoptolidins A and $\mathrm{H}$ (x-axis). Cancer cells showed higher Cy3 signal compared with healthy PBMCs, suggesting greater uptake of $\mathrm{Cy} 3$ apoptolidin $\mathrm{A}$ and $\mathrm{H}$, corresponding to imaging data in Figure 2.

We also measured phosphorylation-specific ACC (p-ACC; y-axis), a marker indicative of autophagy. ${ }^{3}$ In all cancer cell lines, we observed a proportion of cell subset that showed high p-ACC signal at baseline (DMSO treatment). LN229 glioblastoma cells showed the highest increase in the abundance of this subset, from $2.74 \%$ (DMSO) to $12.39 \%$ and $15.28 \%$ after $\mathrm{Cy} 3$ apoptolidin $\mathrm{A}$ and $\mathrm{H}$ treatments, respectively. The majority (>99\%) of p-ACC expressing LN229 cells after apoptolidin treatments were among the $\mathrm{Cy} 3$-positive cells, or cells that had Cy3 apoptolidin-A and $\mathrm{H}$ uptake. In contrast, healthy human PBMCs did not show an increase in p-ACC expression in response to apoptolidin treatments.

A549 and SW620 cells showed only a minimal increase in abundance of cells expressing p-ACC after treatment with Cy3 apoptolidin-A and H, suggesting that A549 and SW620 cells were relatively insensitive to apoptolidins than LN229 cells at $1 \mathrm{~h}$. However, U87 cells showed no increase in p-ACC activity after short-term treatment with apoptolidins $\mathrm{A} / \mathrm{H}$.

In summary, we have shown the utility of fluorescently labeled glycomacrolides (apoptolidins) in monitoring cellular uptake and response, using confocal microscopy and fluorescent flow cytometry. All human cell types tested showed more than $98 \%$ uptake of apoptolidins after $1 \mathrm{~h}$ of treatment. LN229 cells responded with a markedly increase in p-ACC expressing cells, suggesting their sensitivity to apoptolidins. Even though the responses were not as striking, A549 and SW620 cells also showed minimal increase in p-ACC after 1-hour of apoptolidin treatment, whereas healthy human PBMCs and U87 cells did not. Additional kinetics studies would be required for in-depth characterization of the effects of apoptolidins in other cell types. While the current work was conducted using cell lines, we anticipate this approach will be very useful in the study of heterogeneous cell populations using singlecell proteomics as this will provide quantitative data on healthy versus tumor cell small molecule uptake and response. 


\section{CONFLICT OF INTEREST}

The authors declare no conflict of interest.

\section{ACKNOWLEDGEMENTS}

This research was supported by the National Institutes of Health (CA 059515), Vanderbilt University Discovery grant, the Vanderbilt International Scholars Program (NL), NIH/NCI R00 CA143231 (JMI), Vanderbilt-Ingram Cancer Center (VICC NIH/NCI P50 CA68485), and VICC Ambassadors and Hematology Helping Hand Fund awards. SMD and DE acknowledge support of the Vanderbilt Chemical Biology Interface (CBI) training program (T32 GM065086).

1 Kim, J., Adachi, H., ShinYa, K., Hayakawa, Y. \& Seto, H. Apoptolidin, a new apoptosis inducer in transformed cells from Nocardiopsis sp. J. Antibiot. 50, 628-630 (1997).

2 Salomon, A., Voehringer, D., Herzenberg, L. \& Khosla, C. Apoptolidin, a selective cytotoxic agent, is an inhibitor of FOF1-ATPase. Chem. Biol. 8, 71-80 (2001).

3 Salomon, A., Voehringer, D., Herzenberg, L. \& Khosla, C. Understanding and exploiting the mechanistic basis for selectivity of polyketide inhibitors of FOF1-ATPase. Proc. Natl. Acad. Sci. USA 97, 14766-14771 (2000).

4 Serrill, J. D. et al. Apoptolidins A and C activate AMPK in metabolically sensitive cell types and are mechanistically distinct from oligomycin A. Biochem. Pharmacol. 93, 251-265 (2015)

5 Bachmann, B. O. et al. Light-induced isomerization of apoptolidin A leads to inversion of C2-C3 double bond geometry. Org. Lett. 12, 2944-2947 (2010).

6 Pennington, J., Williams, H., Salomon, A. \& Sulikowski, G. A. Toward a stable apoptolidin derivative: Identification of isoapoptolidin and selective deglycosylation of apoptolidin. Org. Lett. 4, 3823-3825 (2002).

7 Wender, P. A., Gulledge, A., Jankowski, O. \& Seto, H. Isoapoptolidin: Structure and activity of the ring-expanded isomer of apoptolidin. Org. Lett. 4, 3819-3822 (2002).
8 Wender, P. A., Sukopp, M. \& Longcore, K. E. Apoptolidins B and C: Isolation, structure determination, and biological activity. Org. Lett. 7, 3025-3028 (2005).

9 Wender, P. A. \& Longcore, K. E. Isolation, structure determination, and anti-cancer activity of apoptolidin D. Org. Lett. 9, 691-694 (2007).

10 Wender, P. A. \& Longcore, K. E. Apoptolidins E and F, New glycosylated macrolactones isolated from Nocardiopsis sp. Org. Lett. 11, 5474-5477 (2009).

11 Ghidu, V. P. et al. Combined chemical and biosynthetic route to access a new apoptolidin congener. Org. Lett. 11, 3032-3034 (2009).

$12 \mathrm{Du}, \mathrm{Y}$. et al. Biosynthesis of the apoptolidins in Nocardiopsis sp FU 40. Tetrahedron 67, 6568-6575 (2011).

13 Daniel, P., Koert, U. \& Schuppan, J. Apoptolidin: Induction of apoptosis by a natural product. Angew. Chem. Int. Ed. 45, 872-893 (2006).

14 Wehlan, H. et al. Apoptolidin A: Total synthesis and partially glycosylated analogues. Chem. Eur. J 12, 7378-7397 (2006).

15 Ghidu, V. P. et al. Synthesis and evaluation of the cytotoxicity of apoptolidinones A and D. J. Org. Chem. 73, 4949-4955 (2008).

16 DeGuire, S. M. et al. Fluoresent probes of the apoptolidins and their utility in cellular localization studies. Angew. Chem. Int. Ed. 54, 961-964 (2015).

17 Bhattacharya, C., Yu, Z., Rishel, M. J. \& Hecht, S. M. The carbamoylmannose moiety of bleomycin mediates selective tumor cell targeting. Biochemistry 53, 3264-3266 (2014).

18 Madathil, M. M. et al. Modified bleomycin disaccharides exhibiting improved tumor cell targeting. Biochemistry 53, 6800-6810 (2014).

19 Schroeder, B. R. et al. The disaccharide moiety of bleomycin facilitates uptake by cancer cells. J. Am. Chem. Soc. 136, 13641-13656 (2014).

$20 \mathrm{Yu}, \mathrm{Z}$. et al. Selective tumor cell targeting by the disaccharide moiety of bleomycin. J. Am. Chem. Soc. 135, 2883-2886 (2013).

21 Krutzik, P. O., Trejo, A., Schulz, K. R. \& Nolan, G. P. In Flow Cytometry Protocols, Third Edition 699: pp 179-202 (2011).

22 Punfa, W., Yodkeeree, S., Pitchakarn, P., Ampasavate, C. \& Limtrakul, P. Enhancement of cellular uptake and cytotoxicity of curcumin-loaded PLGA nanoparticles by conjugation with anti-P-glycoprotein in drug resistance cancer cells. Acta Pharmacol Sin. 33, 823-831 (2012).

23 Dordal, M. S. et al. Flow cytometric assessment of the cellular pharmacokinetics of fluorescent drugs. Cytometry 20, 307-314 (1995). 